\title{
Experimental study of Fusarium solani: infections in Astacus leptodactylus and Pacifastacus leniusculus (Crustacea, Decapoda)
}

\author{
M. Chinain, A. Vey \\ Institut National de la Recherche Agronomique, Station de Recherches de Pathologie Comparée, UA 1184 du CNRS, \\ F-30380 Saint-Christol-Lez-Alès, France
}

\begin{abstract}
A cuticular infection of crayfish Astacus leptodactylus, characterized by the development of large brown patches on the abdomen, was investigated. This 'brown abdomen disease' is caused by the fungus Fusarium solani. The mycosis was reproduced under experimental conditions in artificially wounded A. leptodactylus and North American crayfish Pacifastacus leniusculus. The importance of wounds and of their location on the crayfish body to the development of the infection was determined. Superficial scratches whether dorsal or ventral generally have little or no effect on either species. Haemorrhagic punctures on tergites and on arthrodial membranes however led to mortalities amongst individuals exposed to F. solani. P. leniusculus was found to be markedly more resistant to infection than was A. leptodactylus. Histological and ultrastructural investigations showed the importance of haemolymph exudates at the surface of wounds in the success of infection. These, together with toxicological experiments, demonstrated that crayfish death in $F$. solani infections is caused by physiological disturbances resulting from interference with the moulting process, together with the presence of toxic metabolites produced by the fungus.
\end{abstract}

\section{INTRODUCTION}

An increasing number of investigators have reported that the Hyphomycete Fusarium solani (Mart.) Appel \& Wollenw. can be responsible for catastrophic epizootics in cultured freshwater and marine crustaceans, and infections have also been observed in wild populations (Johnson 1983). Infections mainly involve the gills and the cuticle.

In the marine environment, penaeid shrimp (Johnson 1974, Lightner 1975, Laramore et al. 1977) and lobsters (Fisher et al. 1978, Alderman 1981) are the most frequently reported hosts for Fusarium solani and mortalities may reach $100 \%$.

In freshwater crustaceans, the first descriptions of cuticular infections were from Atlantoastacus pallipes Lereboullet (Crustacea, Decapoda) (Vey \& Vago 1972). Vey (1981) reported a similar infection in Astacus leptodactylus Escholtz in which large brown patches developed, particularly on the dorsal abdomen, but sometimes also extending to the rest of the abdomen. For this reason the name 'brown abdomen disease' was used. The appearance of these brown patches is a result of a melanisation process which is controlled by a complex enzyme activation cascade ('prophenoloxidase activating system ' $=$ ProPo system) (Söderhall \& Smith 1986). Both thin soft intersegmental areas and thicker calcified areas of the exoskeleton are susceptible to attack by fungal hyphae.

Previous investigators have described the gross signs associated with fusariosis and commented on the potential for serious mortalities which could occur under conditions of intensive aquaculture. They have also emphasized the opportunist nature of Fusarium spp. infections where the establishment of infection appears to be favoured by the presence of existing physical lesions of a type common in artificial culture

The potential economic cost of Fusarium infections, together with current limited understanding of the 
mechanisms of pathogenicity of the fungus, led us to investigate the 'brown abdomen syndrome' in crayfish. Commencing with natural infections we attempted to establish the aetiology and principal characteristics of the disease, then, by using histopathological, ultrastructural and toxicological techniques on artificially infected crayfish, we sought to define conditions which encourage infection and the properties of the pathogen which are responsible for its lethal effects

\section{MATERIAL AND METHODS}

Crayíish. Astacus leptodactylus, obtained from commercial imports from Turkey, were 8 to $12 \mathrm{~cm}$ in length. Juvenile Pacifastacus leniusculus (2nd stage larvae) were reared by artificial incubation at Clouzioux hatchery, France (Cabantous 1975). Adult P. leniusculus, 8 to $12 \mathrm{~cm}$ in length, were collected from Lac Divonne, France, the site of trial naturalisation attempts with this species (Laurent \& Vey 1984). Adult crayfish were held in plastic tanks containing $20 \mathrm{l}$ of water at $19^{\circ} \mathrm{C} \pm 2 \mathrm{C}^{\circ}$ at $\mathrm{pH} 8.0$ and maintained in closed recirculation by means of a pump (Eheim 2016-02). An artificial photoperiod of $12 \mathrm{D}-12 \mathrm{~L}$ was maintained. Juveniles were held in $500 \mathrm{ml}$ containers in aerated water (pump = Rena $20 \mathrm{~L}$ ). All crayfish were provided with air-bricks as shelters to reduce injuries caused by cannibalistic attacks during moulting and were fed twice weekly on carrot and sardine.

Mycological techniques. The strain of Fusarium solani used in experiments was isolated from brown abdominal patches of Astacus leptodactylus. After surface disinfection with $5 \%$ sodium hypochlorite and treatment with an antibiotic solution, cuticular fragments were incubated on malt agar at $25^{\circ} \mathrm{C}$. Broth cultures were produced from spores of $F$. solani seeded into Czapeck-Dox medium (Smith 1947), using glucose as source of carbon, and supplemented with $10 \%$ yeast extract. They were incubated for 7 to $14 \mathrm{~d}$ at $25^{\circ} \mathrm{C}$ in a water bath orbital shaker. Crude filtrates were used, either fresh or lyophilised and concentrated for toxicity trials in vivo and in vitro.

To obtain semi-quantitative estimates of the enzymes present in fresh 'metabolic' extracts of the fungus, tests were made using Apizym test galleries (API, France). The chitinolytic activity of the fungus was investigated by means of cultures of Fusarium solani on a $2 \%$ agar medium supplemented with $0.2 \%$ chitin (Sigma, No. C-31.32)

Experimental infection of crayfish. Haemorrhagic cuticular. wounds were produced with needles $(0.1$ to $0.35 \mathrm{~mm}$ diameter dependent on the size of the individual), after surface disinfection of the area to be wounded. Superficial dorsal or ventral scratches were produced using the tip of a scalpel blade applied to the 4 th and 5 th abdominal segments.

Crayfish were exposed for 36 h to a known concentration of a suspension of spores in $2 \mathrm{l}$ of water for adults of both species, or $400 \mathrm{ml}$ for juveniles of Pacifastacus leniusculus. Confirmation of successful infection was made by examination of fresh mounts of tissues in which the characteristic brown markings of infection were apparent.

Histological and electromicroscopical techniques. Cuticular samples of Astacus leptodactylus were fixed in Sinha's fixative (Humason 1962) and dehydrated in ethanol and butanol. After embedding in Paraplast, sections were cut at 5 to $7 \mu \mathrm{m}$ and stained with Masson Trichrome, modified Azan or PAS with haemalun picro indigo carmine (Martoja \& Martoja 1967).

Cuticle samples intended for ultrastructural investigation were fixed in cacodylate buffered $4 \%$ glutaraldehyde at $4{ }^{\circ} \mathrm{C}$, then postfixed in $0.2 \%$ osmium tetroxide. After dehydration in acetone and embedding in Epon, semithin $(0.5 \mu \mathrm{m})$ sections were cut using an LKB ultramicrotome and stained with toluidine blue. Examination of these semithin sections enabled the selection of areas of interest for ultrathin sections (30 nm) which were stained with lead citrate (Reynolds 1963) and examined in an Hitachi HU 11 electron-microscope at an accelerating voltage of $75 \mathrm{kV}$.

Toxicological techniques. Toxicity tests were made using host crayfish Galleria mellonella L. (Insecta, Lepidoptera), and invertebrate cell cultures. With Astacus leptodactylus, injections of 0.1 or $0.05 \mathrm{ml}$ of fresh filtrate per individual were made through the articular membrane of the 3rd left periopod after surface disinfection of the membrane. Larvae of $G$. mellonella, which are often used for toxicity trials, were obtained from strains cultured in semi-aseptic conditions. Each larva received $8 \mu$ of fresh sterile metabolic extract administered by means of a microinjection apparatus. In vitro trials were carried out using an ovarian cell line from Bombyx morii L. (Insectá, Lepidoptera) (SPC Bm 36) established in 1975 (Quiot 1982) in the Tissue Culture Laboratory at the SaintChristol Station. A culture of Fusarium was grown in the same tissue culture medium Bm 24 (Vago \& Quiot 1969) and its pH adjusted to 6.2. A crude filtrate of the Fusarium culture medium was sterilized by passing through a Seitz filter, diluted by mixing with different proportions of fresh medium and then introduced into $35 \mathrm{~mm}$ diameter petri dishes and seeded with cells of $B$. morii. These were then incubated at $28^{\circ} \mathrm{C}$. Resultant cell density was determined by counting in a Thoma cell after resuspension of the cells by repeated pipetting. Cells were also fixed and stained, using the same methods used for histological preparations, for investigation for possible abnormalities. 


\section{RESULTS}

\section{Natural infections}

Histological investigation demonstrated the presence of hyphae in the area of the brown exoskeletal patches. However, the hyphae were present only in the exoskeleton and the tissues immediately beneath. The mycelial filaments within the exoskeleton were surrounded by a region of melanisation produced by an acellular encapsulation mechanism. This process of melanisation, together with further growth of the mycelium, is responsible for the spread of the typical brown patches on the body surface. Within the host, the fungal hyphae are again melanised, and are also the subject of a haemocytic encapsulation reaction which produces large granulomas (capsules)

After isolation on culture medium, microscopic examination of morphological characteristics enabled identification. Colonies were initially cottony white but progressively developed a characteristic rose violet pigmentation. Two types of Fusarium conidiospore are recognised, 1- or occasionally 2-celled microconidia, and multicellular crescent-shaped macroconidia (Fig. 1a). Microconidia are produced on lateral slightly branching microconidiophores which are up to 300 um in length. The full range of morphological characteristics of the isolates is listed in Table 1, and enabled identification as Fusarium solani (Mart.) Appel \& Wollenw. (Messiaen \& Cassini 1968, Booth 1971).

Determination of the range of enzyme activities present in the fresh metabolic extracts of the pathogen, by means of qualitative and semi-quantitative methods, revealed limited production of exocellular enzymes and in particular a clear deficiency of proteases and chitinase. In contrast, cultures produced an abundance of a $C(8)$ esterase-lipase and a $\beta$-glucosidase. The isolate is now maintained as strain No. 1230 in the culture collection of the Saint-Christol Pathology Laboratory

\section{Experimental induction of mycosis}

\section{Superficial scratches}

When made on tergites, these mechanical lesions did not handicap the crayfish. Rapidly melanised, they were often difficult to see on the dark dorsal exoskeleton. When specimens were wounded and then challenged by this method they showed no gross effects, moulted normally and at postmoult presented a new cuticle with no evidence of scratches.

The arthrodial membrane of the sternites offered less resistance to damage than did the dorsal exoskeleton. Ventral scratches tended to produce scarring as a result of partial separation of the 2 lips of the wound. After melanisation these scratches became very visible. Wounded crayfish, even when exposed to infection, normally remained very active and, at the next moult, completed normal exuviation and no longer showed any evidence of mechanical damage

This was particularly true of Pacifastacus leniusculus in which no mortality following scratches and exposure to infection was noted. In Astacus leptodactylus, in contrast, cases of delayed lethality occurred after some $2 \mathrm{mo}$. Their occurrence is certainly attributable to the fact that in A. leptodactylus the ventral cuticle seems less resistant than that of $P$. leniusculus since even superficial scratches often had a tendency to become haemorrhagic. Furthermore, the development of lethal infections is favoured by the intervention of factors such as the moult, variations in environmental temperature, as well as the infection by the fungus of naturally occurring wounds, particularly at the base or joints of appendages.

\section{Haemorrhagi.c wounds}

Astacus leptodactylus. Uncontaminated dorsal punctures led to less than $10 \%$ mortalities in 2 mo; these could be explained by cases of postmoult cannibalism or by an accidental natural infection via the water of the tanks. From the 25th day after exposure to spore challenge, wounded individuals increasingly weakened and mortalities commenced, which in 4 mo reached $85 \%$. Heavily infected individuals invariably developed a large melanised patch which could extend over all the tergite from the initial zone of perforation. At that point a white fungal outgrowth could be observed. The pigmentation could also reach part of the ventral surface of infected segments and their appendages. The development of the infection was accompanied by abnormalities and by mortalities at the time of moult since individuals were often found to be completely incapable of freeing the exuviae of their abdominal segments.

Pacifastacus leniusculus. In wounded and exposed juvenile crayfish, mortality reached $44 \%$ in $10 \mathrm{~d}$, in individuals wounded dorsally and $20 \%$ when the puncture site was ventral. In the unwounded or unexposed controls, no mortality attributable to Fusarium solani was noted during the same period.

Experiments on Pacifastacus leniusculus produced observations analogous to those on Astacus leptodactyLus. However, the scale of success of infection was visibly less in $P$. leniusculus and the first mortalities were slower to occur. Infected individuals remained active, and retained their normal behaviour of escape and attack, even at a very late stage in the experiment. 

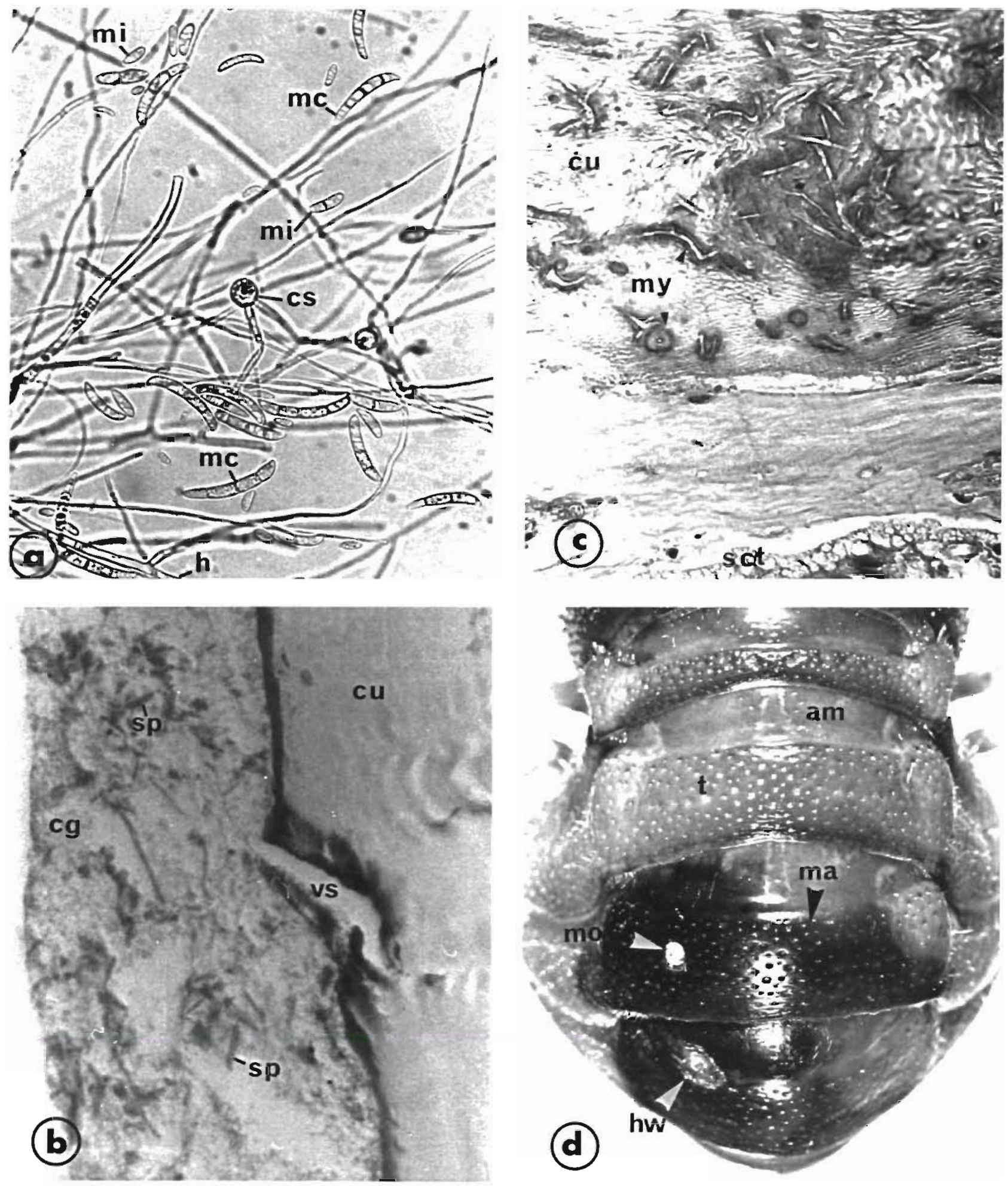

Fig 1 (a) Fusanum solanı Fungal elements. cs chlamydospore, h hyphae, mc: macroconidia; mi: microconıdia ( $\times 450$ ). (b) Astacus leptodactylus Ventral scanfication (vs) at the level of an arthrodial membrane cg: coagulum; sp: spores; cu: cuticle ( $\times 450)$ (c) Pacifastacus leniusculus. Ventral scanfication Development of the mycelium (my) is timited to the cuticle. cu: cuticle; sct subcutıcular tissue $(\times 230)$ (d) Astacus leptodactylus. Haemorrhagic wound $(\mathrm{hw})$ of the integument. ma: melanised areas; tergite, am articular membrane, mo: mycelial outgrowth 
Table 1. Morphological characteristics of Fusarium solani isolated from Astacus leptodactylus

\begin{tabular}{|lllll|}
\hline & Microconidia & Macroconidia & Chlamydospores & Hyphae \\
\hline Shape & $\begin{array}{l}\text { 1-or occasionally } \\
\text { 2-celled. Generally } \\
\text { oblong, sometimes } \\
\text { ovoid }\end{array}$ & $\begin{array}{l}\text { 3-to 6-celled Canoe- } \\
\text { shaped }\end{array}$ & $\begin{array}{l}\text { Globose, smooth or } \\
\text { rough, thick walled }\end{array}$ & $\begin{array}{l}\text { Small diameter, septate, } \\
\text { high growth rate }\end{array}$ \\
Size $(\mu \mathrm{m})$ & $12-22 \times 4-6$ & $35-66 \times 4-8$ & $\varnothing=8-11$ & $\varnothing=4-6$ \\
Culture age & $3 \mathrm{~d}$ & $6 \mathrm{~d}$ & 2 to 3 wk & - \\
\hline
\end{tabular}

\section{Histological and cytological studies of wounded and infected crayfish}

\section{Dorsal scratches}

These consisted of a very superficial abrasion of the epicuticle and only rarely extended in a limited way into the exocuticle. Initial adhesion of the pathogen to the lesion did not appear to occur, since no spores, whether germinated or not, were observed on the surface of the lesions.

\section{Ventral scratches}

These lesions did not develop in the same way because of the difference between the thick, calcified cuticle of the tergites and the thin flexible cuticle of the arthrodial membrane of the sternites. In the latter case the abrasion could reach and affect a significant part or even the whole of the endocuticle, explaining the weeping of haemolymph which may occur and which made possible the attachment of the conidia of Fusarium solani. The resulting variably sized clot became a nutrient medium favouring the germination of spores (Fig. 1b).

In Pacifastacus leniusculus the hyphae which radiated in the exoskeleton from the point of penetration remained exclusively located in the cuticle (Fig. 1c). These were eliminated at the same time as the exuviae in the course of the moult.

The same phenomenon was often observed in Astacus leptodactylus, but in the small number of weakened or dead individuals, a mycelial invasion starting from the damaged areas of exoskeleton was observed together with an attack on the hypodermis and underlying tissues.

\section{Haemorrhagic wounds}

Haemorrhagic wounds produced by puncture took the form of perforations penetrating right through the cuticle resulting in release of haemolymph. The pro- cesses of healing and scar formation in this type of lesion were found to be very rapid as a result of clot formation and the action of haemocytes which rapidly organised into parallel layers under the wound.

In crayfish which were wounded and then exposed to fungal challenge, phases of fungal spore adhesion and germination were also observed (Figs. 2 and 3). From the point of anchorage formed by the haemolymph clot, the mycelial filaments grew in 2 directions, some towards the exterior in the form of a white mycelial clot (Fig. 3a), and some into the thickness of the calcified or membranous cuticle. As in the case of superficial wounds, this development of hyphal growth was accompanied by a strong melanisation which explained the development of the brown patching (Fig. 1d). The fungus also showed a preferential lateral development just on the internal limit of the cuticle where it provoked destruction of the hypodermis (Figs. $2 \mathrm{a}, \mathrm{b})$. After having traversed the scar tissue, which consisted largely of semigranular haemocytes plus a few granulocytes (Fig. 2c), the hyphae induced a spectacular cellular defence reaction in the host tissues, involving haemocytes in the production of a large granulomatous mass. This inflammatory response is similar to the haemocytic reaction described by Solangi \& Lightner (1976) and Hose et al. (1984) in penaeid shrimps. Such a process could prevent the development of new cuticle and in the latter stages of the disease prevented normal moulting of the abdomen (Fig. 3a). At an early stage of the infection, the blood cells which began to organize concentrically around the hyphae did not appear damaged (Fig. 2d). When the mycosis attained a more advanced stage (Fig. 2c), the haemocytes at the center of the concentrically arranged granuloma then appeared partially necrotic: their nuclear chromatin was often sparse and grouped in dense clumps and the nucleoplasm became less electron-opaque. Their cytoplasm was equally degraded and highly vacuolated (Fig. 3b). Such changes were never observed in control individuals but were frequent in the infected zone, suggesting an effect produced by toxic metabolites diffusing out some distance from the hyphae. 

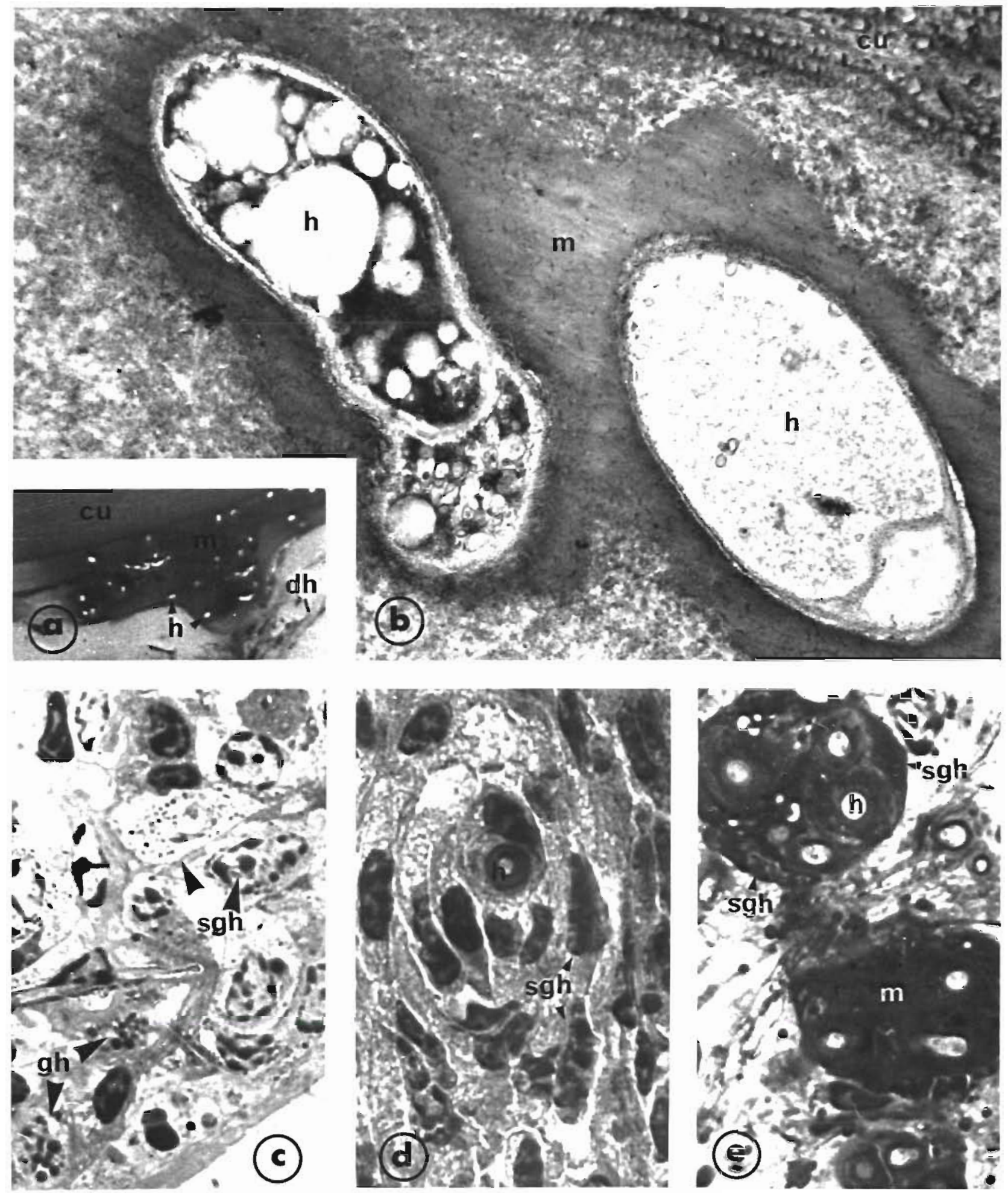

Fig. 2 Fusanum solanı unfecting Astacus laptodactylus $(a, b)$ Lateral growth of $F$ solanı just under the internal limit of the cuticle (a) ( $\times$ 12000); (b) ( $\times 14000)$ h hyphae; cu cuticle; m. melanın, dh damaged hypodermis. (c) Haemocytes intervening in the wound healing process. gh granular haemocytes, shg semigranular haemocytes $(\times 1200)$ (d, e) Haemocytic encapsulation of the fungus in the haemocoel of $A$ leptodactylus at an early stage (d) and advanced stage $(e)$ of the infection $(\times 1200)$ 

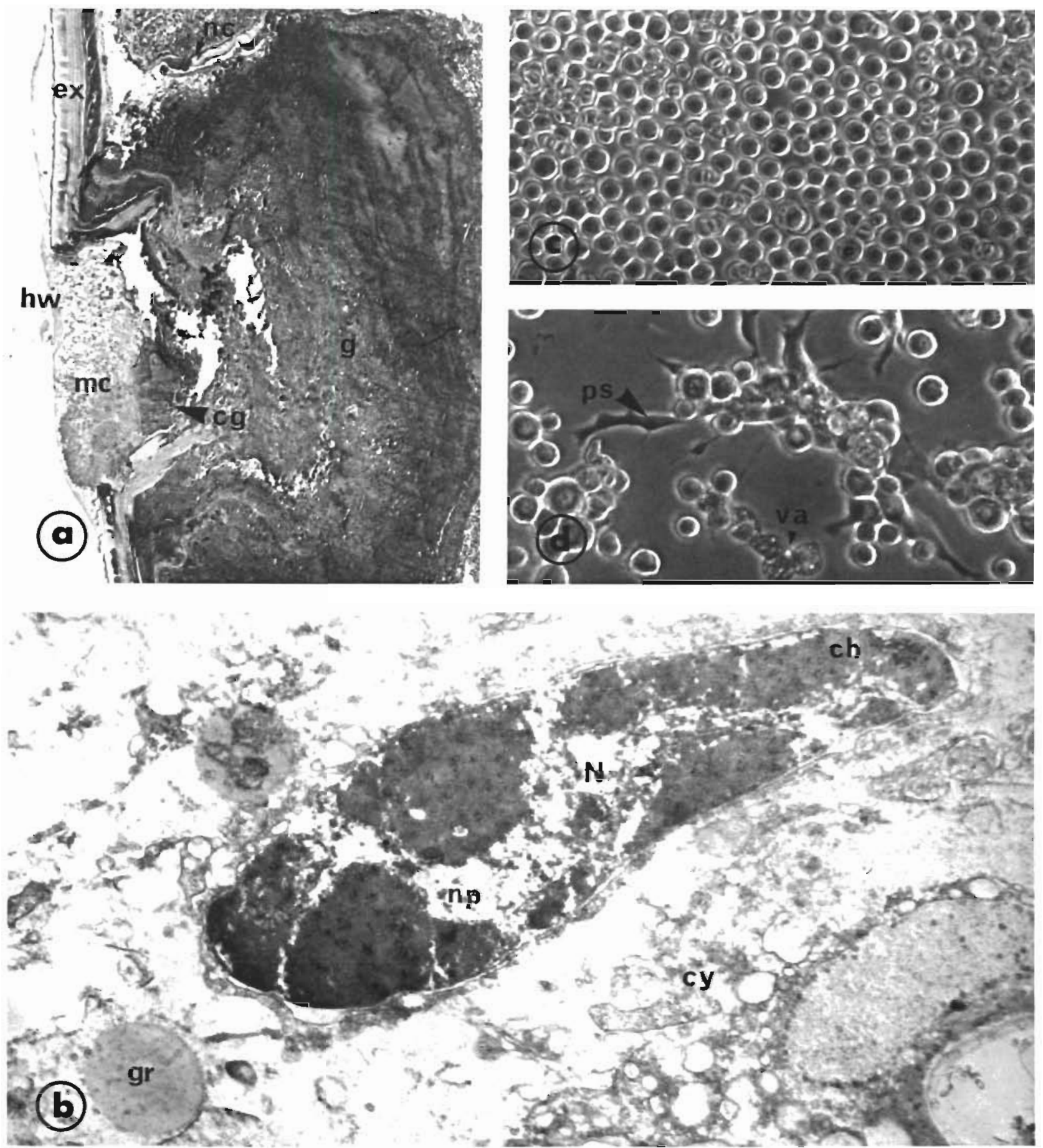

Fig. 3. (a, b) Astacus leptodactylus infected by Fusarium solani. (a) Voluminous haemocytic granuloma resulting from the encapsulation process. hw: haemorrhagic wound; mc: mycelial clot; $\mathrm{cg}$ : coagulum; g: granuloma; nc: neocuticle; ex: exuviae $(\times 30)$. (b) Fine structure of an altered haemocyte. ch: chromatin aggregated in dense masses; cy: altered and vacuolated cytoplasm; gr: intracytoplasmic granule; np: nucleoplasm showing a low electron density; N: nucleus $(\times 1400)$. (c) Control cell culture of the Bombyx mori cell line SPC Bm 36, after 4 d. Note the highly refringent cells and the high cellular density $(\times 560)$. (d) Effect of the filtrate of $F$. solani at the dilution of $1: 4$ on the cells of $B$. mori after $4 \mathrm{~d}$ of contact. Cellular density is low and cells show strong alterations. ps: thin pseudopodia; va: vacuole $(\times 560)$ 


\section{Evidence of toxic effect of Fusarium solani}

To test the hypothesis that exotoxins were involved, filtrates of Fusarium solani were injected into Astacus leptodactylus and into another arthropod host, Galleria mellonella. The solutions administered to crayfish were concentrated 20 -fold by lyophilisation before inoculation, so that their contents of dissolved solids reached $0.16 \mathrm{~g} \mathrm{ml}^{-1}$. The scale of mortality observed in these decapods reached $45 \%$ in a month for a challenge of $0.1 \mathrm{ml}$ per individual and $30 \%$ for a challenge of 0.05 ml. Moribund individuals showed no specific signs.

In Galleria mellonella, the crude unconcentrated filtrate of Fusarium solani induced mortalities equally in larvae, prenymphs and chrysalid stages, finally reaching $90 \%$ in $4 \mathrm{wk}$. The pathogenic effect of the injected fungal material was accompanied by a brown-orange pigmentation either widely distributed or localized in the integument.

Experiments with in vitro cell cultures confirmed the existence of a toxigenic effect in Fusarium solani. Fresh filtrates of that organism grown on medium $\mathrm{Bm} 24$ were tested at dilutions of $1: 10,1: 5$ and $1: 4$. Their toxic effect was evident from the 3rd day in the form of a blocking of cell divisions, and by the appearance, with the 1:4 dilution, of marked cytoplasmic lesions plus some less evident nuclear changes (Fig. 3c, d).

\section{DISCUSSION}

The study of natural cases of brown abdomen disease' in Astacus leptodactylus established that the syndrome was due to attacks by Fusarium solani (Mart.) Appel \& Wollenw. This fungus shows no close adaptation to parasitism of its natural host since it was found to be equally pathogenic for artificially wounded Pacifastacus leniusculus. However, a reduced agressivity of our isolate to this latter species was noticed, that could be explained by the presence of more effective defence reactions against penetration of the pathogen in $P$. leniusculus, as was indicated by Unestam \& Nylund (1972) and Unestam \& Söderhäll (1977) in the case of infection with Aphanomyces astaci Schikora. The intervention of such factors requires further confirmation by histopathological and ultrastructural studies. Experimental contamination of wounds with $F$. solani permitted reproduction of lethal infections in which the gross signs were identical to those of natural infections, and also determination of the method of penetration and of parasitic development of the fungus. The susceptibility of haemorrhagic wounds to infection is explained by the formation of a clot which permits adhesion and germination of spores introduced into the water, followed by a semisaprophytic development of the fungus in the nutritive material forming the clot. Vago (1963) earlier outlined the critical role played by such clots in the success of infections by weakly pathogenic micro-organisms in arthropods.

The fungus, once established locally in the integument, is not able to reach the host tissues and thus provoke a lethal disease unless there is a total or near total discontinuity in the cuticle. Hyphae develop in the interior of the exoskeleton or, at most, immediately beneath it, as well as deeper in host tissue. The hyphae induce an intense cellular defence reaction, which leads to the formation of large granulomas. Hose et al. (1984) have described a very similar evolution of the disease in Penaeus californiensis (Crustacea, Decapoda), artificially wounded and infected by Fusarium solani.

From histopathological and ultrastructural investigations, we have been able to confirm the importance of host defence reactions in the development of pathogenesis in fusarioses. The powerful melanisation that develops around the hyphae, allied to a spectacular process of encapsulation, results in a relatively slow development of the disease.

Despite the fact that infections remained localised, infected crayfish die. The tissue changes observed in vivo appear to result from the action of exotoxins whose production and secretion by Fusarium solani were demonstrated under laboratory conditions in experiments carried out using insects as experimental hosts and in vitro using insect tissue cultures. The formation of large haemocytic aggregates within the host abdominal tissues prevents complete healing of the wounds and, consequently, normal moulting process. The resulting physiological trauma is one of the major causes of mortality.

The results of this study have enabled us to confirm the role played by Fusarium solani in aquaculture and in natural populations of crustaceans in the form of a secondary pathogenic agent. The success of the fungus is dependent on the presence of wounds or on other weakening factors, such as pollutants or other physiochemical factors. Our results throw light onto the mechanisms of action of this organism which is an example of the type of infection process described by Vago (1956). Investigations into separation and more accurate identification of toxic metabolites produced by Fusarium solani are underway. Their purpose is also to characterise the pathogenic effects of these exotoxins at tissue and cellular levels as well as the mechanisms of action at the biochemical level. In parallel, other studies are proposed to investigate in detail the problem of strain variability within the species $F$. solani, where various isolates have been found to be saprophytes, phytopathogens, entomopathogens, or parasites of many species of marine and fresh water crustaceans 
Acknowledgements. The authors thank Dr David Alderman, Fish Diseases Laboratory, Weymouth, UK, for his very efficient help in the translation into English of the manuscript, and for his helpful comments.

\section{LITERATURE CITED}

Alderman, D. J. (1981). Fusarium solani causing an exoskeletal pathology in cultured lobsters, Homarus vulgaris. Trans. Br. mycol. Soc. 76: 25-27

Booth, C. (1971). The genus Fusarium. Commonwealth Mycological Institute, Kew

Cabantous, M. A. (1975). Introduction and rearing of Pacifastacus at the Research Center of Les Clouzioux, 18450 Brignon sur Sauldre, France, Vol. 2. In: Avault, J. W. (ed.) Freshwater crayfish. Louisiana State Univ., Bâton-Rouge, p. 49-55

Fisher, W. W., Wilson, E. M., Steenbergen, J. F., Lightner, D. $V$ (1978). Microbial disease of cultured lobsters: a review. Aquaculture 14: 115-140

Hose, J. E., Lightner, D. V., Redman, R. M., Danald, D. A. (1984). Observations on the pathogenesis of the Imperfect Fungus, Fusarium solani, in the California brown shrimp, Penaeus californiensis. J. Invertebr. Pathol. 44: 292-303

Humason, G. L. (1962). Animal tissue techniques. W. H. Freeman \& Co., San Francisco

Johnson, S. K. (1974). Fusarium sp. in laboratory-held pink shrimp. Texas A\&M Univ., Texas Agric. Ext. Serv. Fish Disease Diagnostic Laboratory, Publ. FDDL No. 1

Johnson, P. T (1983). Diseases caused by viruses, Rickettsiae, bacteria, and Fungi. In: Provenzano, A. J. (ed.) The biology of Crustacea. VI. Pathobiology. Academic Press, New York, p. $1-78$

Laramore, C. R., Barkate, J. A., Persyn, H. O. (1977). Fusarium infection in eyes of mature shrimp, Penaeus vannamei. Texas A \& M Univ., Texas Agric. Ext. Serv. Fish Disease Diagnostic Laboratory, Publ. FDDL No. 59

Laurent, P. J., Vey, A. (1984). The acclimatation of Pacifastacus leniusculus Dana in Lake Divonne. In: Brinck, P. (ed.) Freshwater crayfish Vol. 6. Lund, Sweden, p. 146-155

Lightner, D. V. (1975). Some potentially serious diseases problems in the culture of penaeid shrimp in North America.
Proc. U.S.-Japan Natural Resources Program, Aquaculture Diseases Symposium, Tokyo, p. 75-97

Martoja, R., Martoja, M. (1967). Initiation aux techniques de l'histologie animale. Masson \& Co. Paris

Messiaen, C. M., Cassini, R. (1968). Recherches sur les fusarioses. IV La systématique de Fusarium. Ann. Epiphyties 19: 387-454

Quiot, J. M. (1982). Etablissement d'une lignée cellulaire (SPC $\mathrm{Bm} 36$ ) à partir d'ovaires de Bombyx mori L. (Lepidoptera). Sericologia 22: 25-31

Reynolds, E. S. (1963). The use of lead citrate at high pH as an electron opaque stain in electron microscopy. J. Cell. Biol. 17: 208-212

Smith, G. (1947). An introduction to industrial mycology. E Arnold \& Co., London

Söderhäll, K., Smith, V. J. (1986). Prophenoloxydase-Activating Cascade as a recognition and defence system in arthropods. In: Gupta, A. P. (ed.) Hemocytic and humoral immunity in arthropods. John Wiley \& Sons, p. 251-286

Solangi, M. A., Lightner, D. V (1976). Cellular inflammatory response of Penaeus aztecus and $P$. setiferus to the pathogenic fungus, Fusarium sp., isolated from the California brown shrimp, P. californiensis. J. Invertebr. Pathol. 27. $77-86$

Unestam, T., Nylund, J. (1972). Blood reactions in vitro in crayfish against a fungal parasite, Aphanomyces astaci. J. Invertebr Pathol. 19: 94-106

Unestam, T., Söderhäll, K. (1977). Specialization in crayfish defence and fungal aggressiveness upon crayfish plague infection. In: Lindquist, O. V (ed.) Freshwater crayfish Vol. 3. Kuopio, Finland, p. 321-331

Vago, C. (1956). L'enchainement des maladies chez les insectes. Edition Speciale Commission Sericole International, Alès, France

Vago, C. (1963). Predispositions and interrelations in insect diseases. In: Steinhaus, E. A. (ed.) Insect pathology, Vol. 1. Academic Press, New York, p. 339-379

Vago, C., Quiot, J. M. (1969). Recherches sur la composition des milieux pour cultures de cellules d'invertébrés. Ann. Zool. Ecol. Anim. 1: 281-288

Vey, A. (1981). Les maladies des écrevisses, leur reconnaissance et la surveillance sanitaire des populations astacicoles. Bull. Fr. Piscic. 281: 223-236

Vey, A., Vago, C. (1972). Recherches sur les maladies actuelles des écrevisses en France. Ann. Hydrobiol. 3: 59-64 